\title{
Cardio classics revisited: focus on the role of amlodipine
}

\author{
This article was published in the following Dove Press journal: \\ Integrated Blood Pressure Control \\ 5 January 2012 \\ Number of times this article has been viewed
}

\author{
Alice J Owen \\ Christopher M Reid \\ Centre of Cardiovascular Research \\ and Education in Therapeutics, \\ Department of Epidemiology and \\ Preventive Medicine, Monash \\ University, Melbourne, Victoria, \\ Australia
}

\begin{abstract}
Amlodipine is a long-acting, dihydropyridine calcium antagonist now widely used for lowering of elevated blood pressure. In recent years it has been shown to be effective in reducing both blood pressure and risk of cardiovascular $(\mathrm{CV})$ events when used in combination with other antihypertensive agents of different classes. Strong evidence of cardiovascular benefit has been attained for combination of amlodipine with diuretics or angiotensin converting enzyme (ACE) inhibitors in a number of high-risk CV groups, including those with established coronary artery disease, diabetes, and at risk of renal disease. Combination therapies of amlodipine with other agents eliciting renin-angiotensin-aldosterone system blockade (angiotensin II receptor blockers or renin inhibitors) have been shown to be effective blood pressure-lowering strategies, but await the results of ongoing trials for direct evidence of benefit for renal disease progression and CV morbidity and mortality.
\end{abstract}

Keywords: hypertension, amlodipine, cardiovascular disease, calcium antagonist, antihypertensive

\section{Introduction}

The most widespread clinical use of calcium channel blockers or calcium antagonists is in the management of elevated blood pressure (BP). The BP-lowering effects of this class of drugs are mediated by binding to calcium channels which inhibits the transmembrane influx of calcium into vascular smooth muscle cells and cardiac muscle cells. As calcium influx drives contractile activity of these muscle cells, the resultant lowering of cytosolic free calcium elicits potent peripheral arterial vasodilatation, and in the heart results in increased blood flow to cardiac muscle. Amlodipine is a third generation dihydropyridine calcium antagonist which demonstrates high selectivity for vascular smooth muscle, with minimal impact upon heart rate, and no negative ionotropic effects or electrophysiological disturbances. In addition to its antihypertensive and antianginal properties, amlopidine has also been suggested to inhibit vascular smooth muscle cell proliferation and exhibit antiatherosclerotic effects. Amlodipine has a high bioavailability, higher volume of distribution, and prolonged half-life compared to other calcium antagonists making it more suitable for once a day administration. ${ }^{1}$

\section{Amlodipine in prevention of cardiovascular disease}

The advantage of a longer duration of antihypertensive effect for amlodipine over short-acting calcium antagonists raised the question of how it compared to other firstline antihypertensive agents in reducing the risk of cardiovascular disease (CVD). Evidence from the early trials was inconsistent. Trials such as the Treatment of Mild 
Hypertension Study (TOMHS) found amlodipine was as effective as other commonly used classes of hypertensive agent in preventing cardiovascular events. ${ }^{2}$ Conversely, the Fosinopril versus Amlodipine Cardiovascular Events Trial (FACET) in patients with hypertension and diabetes reported that despite amlodipine having a greater antihypertensive effect, there was a significantly lower rate of major vascular events in the fosinopril group compared to the amlodipine group (hazard ratio [HR]: 0.49; $95 \%$ confidence interval $[\mathrm{CI}]: 0.26-0.95 ; P=0.03){ }^{3}$ This uncertainty was reflected in two meta-analyses published in the Lancet in 2000 raising great debate around the role of calcium channel blockers as first-line therapy in hypertension. The first meta-analysis by Pahor and colleagues $(n=27,743)$ concluded that intermediate/long-acting calcium antagonists were inferior to other antihypertensive therapies in the prevention of major cardiovascular events. ${ }^{4}$ Conversely, the second meta-analysis undertaken by the Blood Pressure Lowering Treatment Trialists' Collaboration $(n=74,696)$ found no superiority nor inferiority of calcium antagonists compared to other antihypertensive agents for reducing major cardiovascular events. ${ }^{5}$ Further research was clearly needed to establish the relative cardiovascular benefit of amlodipine in hypertension, but also within high-risk subgroups such as those with diabetes, renal disease, older individuals, and ethnicities known to be at higher CVD risk (such as African Americans, ${ }^{6}$ Australian Aboriginals, ${ }^{7}$ and South Asians living in the UK). ${ }^{8}$

In the first decade of this century a number of large scale clinical trials have informed our understanding of the effect of amlodipine on risk of cardiovascular disease. Over this period there has also been a shift in focus toward the use of amlodipine as part of a multiple-antihypertensive agent approach to treatment of high blood pressure.

\section{Landmark trials in patients at elevated risk of CVD}

The Antihypertensive and Lipid-Lowering Treatment to Prevent Heart Attack Trial (ALLHAT) enrolled 33,357 participants aged over 55 years with hypertension and at least one coronary heart disease (CHD) risk factor in a randomized, double-blind trial comparing three antihypertensive interventions; a calcium antagonist (amlodipine), an angiotensin converting enzyme (ACE)-inhibitor (lisinopril), and a diuretic (chlorthalidone). With a mean follow up of 4.9 years, ALLHAT found no difference in the primary outcome (combined fatal CHD or nonfatal myocardial infarction) between the amlodipine and diuretic groups (relative risk
[RR]: 0.98, 95\% CI: 0.90-1.07; $P=0.65$; Figure 1$).{ }^{9}$ The size and quality of the ALLHAT trial design provided convincing evidence to refute the suggestions that amlodipine might be inferior in reducing major cardiovascular events, and the lack of any difference between amlodipine and diuretic on the primary outcome was consistent across risk subgroups (based upon age, sex, race, diabetes). However, compared to the thiazide diuretic, amlodipine was associated with an increased 6-year risk of heart failure (RR: 1.38, 95\% CI: $1.25-1.52 ; P<0.001){ }^{9}$

In patients with established coronary artery disease, the Prospective Randomized Evaluation of the Vascular Effects of Norvasc Trial (PREVENT) undertook a placebocontrolled trial of amlodipine to determine the effect upon atherosclerotic progression. PREVENT found no effect of amlodipine on mean minimal vessel diameter, but noted a significant effect of amlodipine in slowing the progression of carotid artery atherosclerosis. There was however no effect of amlodipine on rates of all-cause mortality or cardiovascular events. ${ }^{10}$ However in the CAMELOT study, which compared amlodipine or enalapril vs placebo in patients with coronary artery disease but with normal blood pressure, amlodipine was shown to be associated with a reduced risk of adverse cardiovascular events. The trend towards a slowing of atherosclerosis progression was only significant in those with higher systolic blood pressure. ${ }^{11}$

The Valsartan Antihypertensive Long-term Use Evaluation (VALUE) trial compared amlodipine to the angiotensin receptor antagonist valsartan in 15,245 patients over 50 years of age with hypertension and high risk of CVD. ${ }^{12}$ VALUE found no difference between the two groups in the composite cardiac morbidity and mortality endpoint, despite blood pressure being lowered to a greater extent by amlodipine. In analysis of the secondary endpoints, myocardial infarction (MI) was significantly more frequent in the valsartan group (HR: $1.19,95 \%$ CI: $1.02-1.38 ; P=0.02$ ), but there were significantly fewer cases of new-onset diabetes in the valsartan group compared to the amlodipine group (HR: 0.77, 95\% CI: 0.69-0.86; $P<0.001)$. The results of VALUE also highlighted the difficulty in achieving BP targets with antihypertensive monotherapy. Upon completion of the study, or reaching a primary endpoint, only $35 \%$ of the amlodipine group and $27 \%$ of the valsartan group remained on their randomized single-agent therapy (with predefined schedules for treatment intensification in order to meet blood pressure targets in-study).

Trials such as VALUE, amongst others, highlighted that the majority of patients require more than one 
antihypertensive agent to reach blood pressure targets. ${ }^{12}$ The question of what represents the optimal combination of antihypertensive agents has been addressed by a number of large scale studies including the Anglo-Scandinavian Cardiac Outcomes Trial-Blood Pressure Lowering Arm (ASCOTBPLA). ASCOT-BPLA was a prospective randomized controlled trial in 19,257 patients with hypertension plus at least three other CVD risk factors. ${ }^{13}$ Participants were assigned to either amlodipine (+perindopril as required) or atenolol (+bendroflumethiazide as required). ASCOT-BPLA was stopped prematurely based upon the finding that compared to the amlodipine group, those in the atenolol group had significantly higher mortality and worse outcomes on a number of secondary endpoints. Although the primary outcome measure of nonfatal MI and fatal CHD failed to reach significance (HR: $0.90,95 \%$ CI: $0.79-1.02 ; P=0.105$ ), those on the amlodipine-based regimen had significantly lower rates of cardiovascular mortality (HR: $0.76,95 \%$ CI: $0.66-0.89$; $P=0.001$ ) and total coronary events and procedures (HR: 0.84, 95\% CI: $0.78-0.90 ; P<0.0001)$ than those on the atenolol-based regimen.

More recently, the Avoiding Cardiovascular Events through Combination Therapy in Patients Living with Systolic Hypertension (ACCOMPLISH) trial examined the combination of ACE-inhibitor (benazepril) plus amlodipine compared to benazepril plus the diuretic hydrochlorothiazide for the treatment of hypertension in 11,506 high CVD risk patients. With a primary endpoint encompassing CVD death, MI, stroke, angina, resuscitation after sudden cardiac arrest, and coronary revascularization, ACCOMPLISH found that the benazepril-amlodipine combination afforded significantly greater protection against cardiovascular events than the benazepril-hydrochlorothiazide combination (RR: 0.80, 95\% CI: 0.72-0.90; $P<0.001) .{ }^{14}$

\section{Amlodipine and heart failure}

Treatment with short-acting calcium antagonists had been found to worsen heart failure and increase risk of death in patients with significant left ventricular dysfunction. ${ }^{15,16}$ This was suggested to be due to the tendency of these shorter-acting calcium antagonists to depress cardiac contractility and activate neurohormonal systems. Whether amlodipine also increased morbidity and mortality in this patient group was addressed by the Prospective Randomized Amlodipine Survival Evaluation (PRAISE) study. PRAISE randomly allocated 1153 patients with chronic heart failure (HF) class IIIB or IV and a left ventricular ejection fraction of less than $30 \%$ to either placebo or amlodipine on top of usual therapy. Amlodipine was found not to adversely impact morbidity or mortality in this population of CHF patients (amlodipine vs placebo, RR: 0.91, 95\% CI: $0.76-1.10 ; P=0.31) .{ }^{17}$ Upon examination of adverse effects, amlodipine was associated with increased risk of peripheral and pulmonary edema, but a reduced risk of uncontrolled hypertension. While the results of PRAISE suggested that amlodipine could be safely used in HF, there was no substantial mortality or morbidity benefit suggesting that their routine use would be limited in this patient group.

In those with hypertension but without overt heart failure, ALLHAT found that amlodipine was associated with an increased 6-year risk of heart failure compared to a thiazide diuretic (RR: $1.38,95 \%$ CI: $1.25-1.52) .{ }^{9}$ However both the VALUE and the Candesartan Antihypertensive Survival Evaluation in Japan (CASE-J) studies found no difference in risk of heart failure for amlodipine compared with angiotensin receptor antagonists (valsartan vs amlodipine, HR: $0.89,95 \%$ CI: $0.87-1.03 ; P=0.12,{ }^{12}$ and candesartan vs amlodipine, HR: $1.25,95 \%$ CI: $0.65-2.42 ; P=0.50) .{ }^{18}$

\section{Amlodipine and angina}

Shorter-term trials have demonstrated the antianginal efficacy of amlodipine, ${ }^{19}$ thought to be mediated by the amlodipine-induced dilation of coronary arteries and reduction in total peripheral resistance, decreasing the occurrence of symptomatic angina, and silent MI. In the PREVENT trial those with a history of angina comprised $68 \%$ of the participant group, and compared to placebo, amlodipine significantly reduced hospitalization for unstable angina (HR: $0.67,95 \%$ CI: $0.48-0.93$ ). ${ }^{10}$ However whether amlodipine offers a level of long term antianginal benefit beyond other antihypertensives remains unclear. In ALLHAT there was no significant difference in hospitalization/treatment for angina between the amlodipine and diuretic groups (RR: 1.02, 95\% CI: 0.94-1.10). ${ }^{9}$ ACCOMPLISH found no effect of amlodipine in combination with benazepril vs benazepril + hydrochlorothiazide on hospitalization for unstable angina (HR: $0.75,95 \%$ CI: 0.50-1.10). In ASCOTBPLA, amlodipine vs atenolol significantly reduced unstable angina (HR: $0.68,95 \%$ CI: $0.51-0.92 ; P=0.0115$ ) but had no significant effect on chronic stable angina (HR: 0.98, 95\% CI: $0.81-1.19) .{ }^{13}$

Those with angina have had significant representation in outcome-driven trials of amlodipine and there is no evidence of diminished effectiveness of amlodipine for prevention of secondary CVD in this population group. 

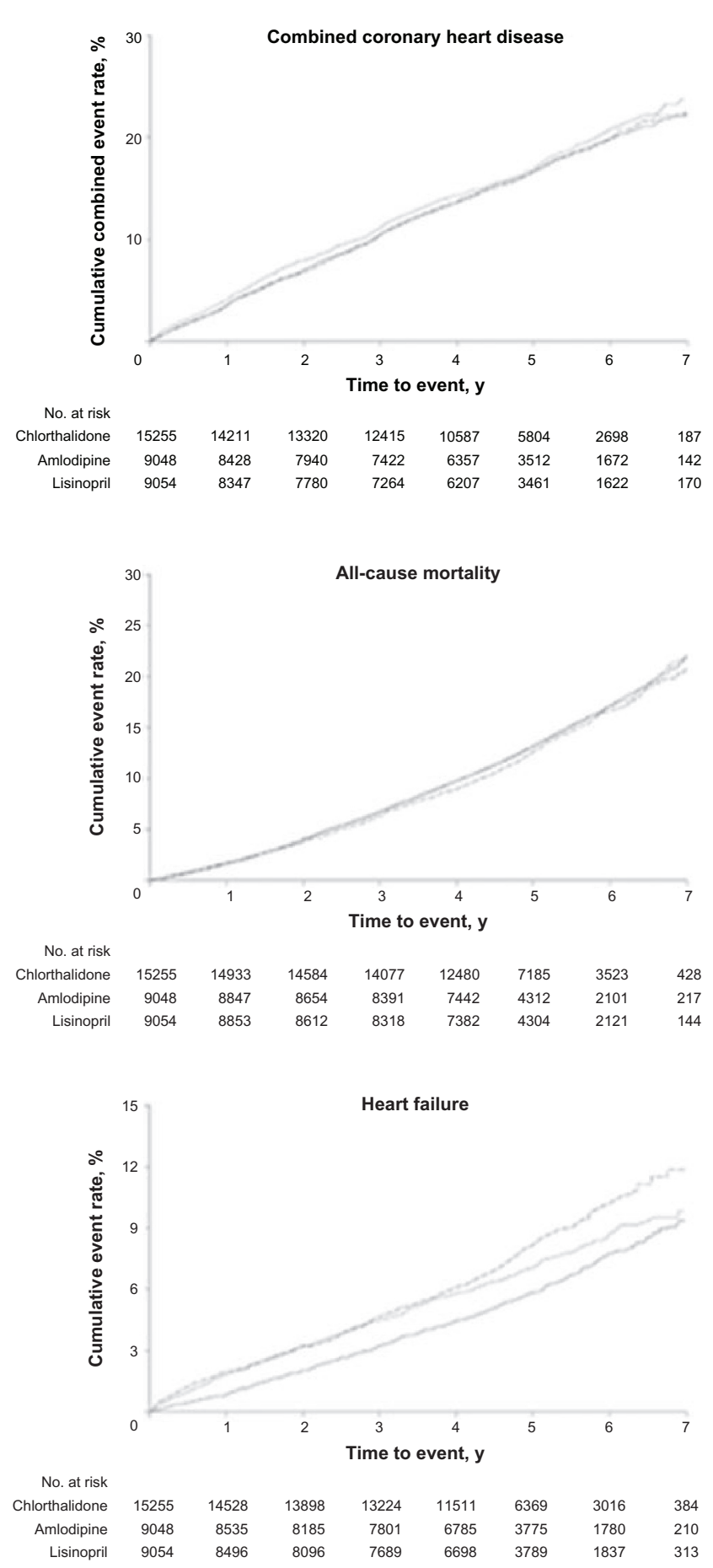

Figure I Cumulative event rates in ALLHAT (Antihypertensive and Lipid-Lowering Treatment to Prevent Heart Attack Trial). ${ }^{9}$

ALLHAT Research Group. JAMA 2002;288(23):2991. Copyright (C) (2002) American Medical Association. All rights reserved.

\section{Amlodipine and renal disease outcomes}

Hypertension is a major cause of end stage renal disease (ESRD), and blood pressure levels have been shown to be correlated with renal disease progression. ${ }^{20,21}$ The optimal antihypertensive therapeutic strategies for prevention of renal failure in addition to reducing risk of cardiovascular morbidity and mortality remain to be clarified, particularly within risk subgroups.

In primary agent comparisons, ALLHAT found no significant differences between amlodipine vs diuretic in the development of ESRD or renal disease progression (by estimated glomerular filtration rate [GFR]) in high risk hypertensive patients. ${ }^{9,22}$ CASE-J also noted no significant difference in rates of renal events between candesartan- and amlodipine-treated high-risk hypertensive patients (HR: 0.70, 95\% CI: 0.39-1.26; $P=0.23) .{ }^{18}$ The African American Study of Kidney Disease and Hypertension (AASK) randomized 1094 African Americans with hypertension and renal insufficiency to either a beta-blocker (metoprolol), ACE-inhibitor (ramipril), or amlodipine and examined progression of renal disease over a 3-6 year follow-up. ${ }^{23,24}$ With a composite clinical endpoint comprising reduction in GFR, ESRD, or death, AASK found that compared to amlodipine, treatment with ramipril resulted in a $38 \%$ relative risk reduction in clinical events (RR: $0.62,95 \%$ CI: $0.44-0.87 ; P=0.005$ ). In this study ramipril was also more effective than both amlodipine and metoprolol in slowing the rate of decline in GFR, supporting the use of renin-angiotensin system (RAS) blockade as an integral part of a strategy for blood pressure lowering in nephropathy.

\section{Fixed dose combinations}

What type of antihypertensive agent might best complement ACE-inhibition as part of a fixed combination treatment was addressed in a prespecified secondary analysis of the ACCOMPLISH study. ${ }^{25}$ ACCOMPLISH found that using the progression of chronic kidney disease endpoint comprised of doubling of serum creatinine, ESRD, and dialysis, treatment with an ACE-inhibitor (benazepril) plus amlodipine was associated with significantly reduced risk of kidney disease progression compared to treatment with ACEinhibitor plus a diuretic (hydrochlorothiazide) (HR: 0.52, 95\% CI: $0.41-0.65 ; P<0.0001)$. Similar results were found for the composite endpoint of chronic renal disease plus cardiovascular death. Rates of peripheral edema were higher in the benazepril + amlodipine group, but rates of dizziness and hypotension were lower compared to the benazepril + hydrochlorothiazide group. ACCOMPLISH concluded that as part of an antihypertensive treatment strategy, benazepril + amlodipine offered significant benefit for preventing renal disease progression over benazepril + hydrochlorothiazide. 
Table I Characteristics of major amlodipine trials

\begin{tabular}{|c|c|c|c|c|}
\hline Study (ref) & Agents studied & Disease state & $\mathbf{N}$ & Outcome measures \\
\hline \multicolumn{5}{|c|}{ Single antihypertensive agent comparison trials } \\
\hline TOMHS ${ }^{2}$ & $\begin{array}{l}\text { Placebo vs chlorthalidone vs } \\
\text { acebutolol vs doxazosin vs } \\
\text { amlodipine vs enalapril }\end{array}$ & Mild hypertension & 902 & BP, CVD events \\
\hline ALLHAT ${ }^{9}$ & $\begin{array}{l}\text { Chlorthalidone vs } \\
\text { amlodipine vs lisinopril }\end{array}$ & $\begin{array}{l}\text { Hypertension }+\geq 1 \text { other } \\
\text { CVD risk factor }\end{array}$ & 33,357 & CVD events, BP \\
\hline PREVENT $^{10}$ & Placebo vs amlodopine & Established coronary artery disease & 825 & $\begin{array}{l}\text { CVD events, atherosclerotic } \\
\text { disease progression }\end{array}$ \\
\hline AASK $^{24}$ & $\begin{array}{l}\text { Metoprolol vs } \\
\text { amlodipine vs ramipril }\end{array}$ & Hypertensive renal disease & 1094 & $\begin{array}{l}\text { Renal disease } \\
\text { progression, BP }\end{array}$ \\
\hline CAMELOT"I & $\begin{array}{l}\text { Amlodipine vs enalapril vs } \\
\text { placebo }\end{array}$ & $\begin{array}{l}\text { Established coronary artery disease + } \\
\text { normal blood pressure }\end{array}$ & 1991 & CVD events \\
\hline VALUE $^{12}$ & Valsartan vs amlodipine & Hypertension at high CVD risk & 15,245 & $\begin{array}{l}\text { CVD mortality and } \\
\text { morbidity }\end{array}$ \\
\hline CASE-J 18 & Candesartan vs amlodipine & Hypertension at high CVD risk & 4728 & $\begin{array}{l}\text { CVD mortality and } \\
\text { morbidity, diabetes onset }\end{array}$ \\
\hline FACET $^{3}$ & Fosinopril vs amlodipine & Hypertension + diabetes & 380 & CVD events, BP \\
\hline \multicolumn{5}{|c|}{ Combination antihypertensive agent therapy trials } \\
\hline ASCOT-BPLA $^{13}$ & $\begin{array}{l}\text { Amlodipine } \pm \text { perindopril vs } \\
\text { atenolol } \pm \text { bendroflumethiazide }\end{array}$ & $\begin{array}{l}\text { Hypertension }+\geq 3 \text { other } \\
\text { CVD risk factors }\end{array}$ & 19,257 & Nonfatal MI, CVD mortality \\
\hline PRAISE $^{17}$ & $\begin{array}{l}\text { Amlodipine }+\mathrm{ACEi}+\text { diuretic vs } \\
\text { placebo }+\mathrm{ACEi}+\text { diuretic }\end{array}$ & Heart failure & 1153 & Mortality, CVD morbidity \\
\hline ACCOMPLISH $^{14}$ & $\begin{array}{l}\text { Benzepril + amlodipine vs } \\
\text { Benzepril + hydrochlorothiazide }\end{array}$ & Hypertension at high CVD risk & 11,506 & $\begin{array}{l}\text { CVD mortality, CVD } \\
\text { events, renal outcomes }\end{array}$ \\
\hline
\end{tabular}

Abbreviations: TOMHS, Treatment of Mild Hypertension Study; ALLHAT, Antihypertensive and Lipid-Lowering Treatment to Prevent Heart Attack Trial; PREVENT, Prospective Randomized Evaluation of the Vascular Effects of Norvask Trial; AASK, African American Study of Kidney Disease and Hypertension; VALUE, Valsartan Antihypertensive Long-term Use Evaluation; CASE-J, Candesartan Antihypertensive Survival Evaluation in Japan; FACET, Fosinopril Versus Amlodipine Cardiovascular Events Randomized Trial; ASCOT-BPLA, Anglo-Scandinavian Cardiac Outcomes Trial-Blood Pressure Lowering Arm; PRAISE, Prospective Randomized Amlodipline Survival Evaluation; ACCOMPLISH, Avoiding Cardiovascular Events through Combination Therapy in Patients Living with Systolic Hypertension.

\section{Diabetes}

Large scale studies such as ASCOT-BPLA have examined the effect of antihypertensive agents on new-onset diabetes in an at-risk cohort. ASCOT-BPLA found significantly fewer cases of new onset diabetes in the amlodipine/perindopril vs atenolol/thiazide diuretic antihypertensive regimen (HR: 0.70, 95\% CI: $0.63-0.78 ; P<0.0001)$. Consistent with this, ALLHAT also noted that diuretics were associated with a greater number of cases of new onset diabetes compared to amlodipine (OR: $0.73,95 \%$ CI: $0.58-0.91 ; P<0.01$ ). These studies highlighted a slightly increased risk of new onset diabetes with diuretics, although in both cases this increase in risk of diabetes did not translate to any measurable impact on cardiovascular disease risk.

In studies comparing amlodipine to angiotensin receptor blockers, the VALUE study found significantly fewer

Table 2 Amlodipine combinations

\begin{tabular}{|c|c|c|c|}
\hline & Combination agent & Present level of evidence & Evidence of benefit in: \\
\hline \multicolumn{4}{|c|}{ Amlodipine } \\
\hline \multirow[t]{2}{*}{ Plus } & Thiazide diuretics & CV outcomes & Hypertension at high CVD risk \\
\hline & & BP-lowering & \\
\hline \multirow[t]{3}{*}{ Plus } & ACE inhibitor & CV outcomes & Hypertension at high CVD risk \\
\hline & & BP-lowering & Established CAD \\
\hline & & Renal disease progression & Diabetes \\
\hline Plus & ARB & BP-lowering & Hypertension \\
\hline Plus & Renin inhibitor & BP-lowering & Hypertension \\
\hline Plus & Beta-blocker & BP-lowering & Hypertension at high CVD risk \\
\hline \multirow[t]{2}{*}{ Plus } & Statin & BP- (and lipid-) lowering & Those at increased CVD risk \\
\hline & & & due to hypertension + hyperlipidemia \\
\hline
\end{tabular}

Abbreviations: CV, cardiovascular; BP, blood pressure; ACE, angiotensin converting enzyme; CAD, coronary artery disease; CVD, cardiovascular disease; ARB, angiotensin II receptor blocker. 
cases of new-onset diabetes in the valsartan group compared to the amlodipine group (HR: $0.77,95 \% \mathrm{CI}$ : 0.69-0.86; $P<0.001) .{ }^{12}$ CASE-J noted a $36 \%$ relative risk reduction in new onset diabetes in the candesartan arm compared to the amlodipine arm (RR: $0.64,95 \% \mathrm{CI}: 0.43-0.97, P=0.033) .{ }^{18}$ Overall, trials to date suggest that amlodipine has little influence on new-onset diabetes.

Those with established diabetes are at greater increased risk of cardiovascular and renal disease, and management of hypertension in diabetes is crucial for reducing risk of events. With diabetes being a major CVD risk factor, this patient population often represents a significant subgroup within hypertension trials. In ACCOMPLISH, 60\% of the study population had diabetes, and in this subgroup the superiority of the benazepril/amlodipine combination over the benazepril/hydrochlorothiazide combination was consistent (HR: 0.79 , 95\% CI: $0.68-0.92 ; P=0.003$ ) with that seen in the whole study population ${ }^{14}$ (Table 2 ). Those with diabetes made up approximately $18 \%$ of the ASCOT-BPLA study population with the cardioprotective superiority of amlodipine retained amongst the diabetes subgroup (HR: 0.87, 95\% CI: $0.76-0.99 ; P=0.03) .{ }^{13}$

\section{Other amlodipine combination therapies}

Blood pressure-lowering efficacy has been shown for combinations of amlodipine with angiotensin receptor blockers ${ }^{26}$ and renin inhibitors, ${ }^{27}$ and based upon the complementary mechanisms of action of these agents it would be logical to suggest that they would produce at least similar reductions in CVD risk. Trials examining effects of amlodipine/newer RAS blockade agents on CVD outcomes are underway and results pending. ${ }^{28}$

\section{Conclusion}

Amlodipine monotherapy has been shown to be not inferior to other antihypertensive agents in reducing blood pressure; however the majority of those with hypertension require more than one antihypertensive agent to achieve blood pressure control. Amlodipine appears to offer significant benefit as a second-line antihypertensive therapy, and may also influence CVD progression/development through BP-independent effects. The ACCOMPLISH study found that amlodipine in combination with an ACE-inhibitor reduces CVD mortality and morbidity, in addition to reducing progression of kidney disease. Whether combinations using other agents eliciting RAS blockade (such as angiotensin receptor antagonists or renin inhibitors) offer the same benefits for preventing renal disease progression and CVD morbidity and mortality is under investigation in ongoing trials. Since the release of amlodipine in the early 1990s, it still remains one of the top five global pharmaceutical products with US\$5 billion in sales in $2006 .{ }^{29}$ Its effectiveness in lowering blood pressure in addition to high tolerability and minimal side effects has made it an agent of choice in both single and combination drug treatment strategies for reducing the burden of cardiovascular disease across the globe.

\section{Disclosure}

The authors report no conflicts of interest in this work.

\section{References}

1. Abernethy DR. The pharmacokinetic profile of amlodipine. Am Heart J. 1989;118(5):1100-1103.

2. Neaton JD, Grimm RH Jr, Prineas RJ, et al. Treatment of Mild Hypertension Study. Final results. Treatment of Mild Hypertension Study Research Group. JAMA. 1993;270(6):713-724.

3. Tatti P, Pahor M, Byington RP, et al. Outcome results of the Fosinopril Versus Amlodipine Cardiovascular Events Randomized Trial (FACET) in patients with hypertension and NIDDM. Diabetes Care. 1998;21(4):597-603.

4. Pahor M, Psaty BM, Alderman MH, et al. Health outcomes associated with calcium antagonists compared with other first-line antihypertensive therapies: a meta-analysis of Randomized controlled trials. Lancet. 2000;356(9246):1949-1954.

5. Neal B, MacMahon S, Chapman N. Effects of ACE inhibitors, calcium antagonists, and other blood-pressure-lowering drugs: results of prospectively designed overviews of randomized trials. Blood Pressure Lowering Treatment Trialists' Collaboration. Lancet. 2000; 356(9246):1955-1964.

6. Gu Q, Burt VL, Paulose-Ram R, Yoon S, Gillum RF. High blood pressure and cardiovascular disease mortality risk among US adults: the third National Health and Nutrition Examination Survey mortality follow-up study. Ann Epidemiol. 2008;18(4):302-309.

7. Bradshaw PJ, Alfonso HS, Finn J, Owen J, Thompson PL. A comparison of coronary heart disease event rates among urban Australian Aboriginal people and a matched non-Aboriginal population. J Epidemiol Community Health. 2011;65(4):315-319.

8. Lip GY, Barnett AH, Bradbury A, et al. Ethnicity and cardiovascular disease prevention in the United Kingdom: a practical approach to management. J Hum Hypertens. 2007;21(3):183-211.

9. ALLHAT Officers and Coordinators for the ALLHAT Collaborative Research Group. Major outcomes in high-risk hypertensive patients randomized to angiotensin-converting enzyme inhibitor or calcium channel blocker vs diuretic: The Antihypertensive and LipidLowering Treatment to Prevent Heart Attack Trial (ALLHAT). JAMA. 2002;288:2981-2997.

10. Pitt B, Byington RP, Furberg CD, et al. Effect of amlodipine on the progression of atherosclerosis and the occurrence of clinical events. PREVENT Investigators. Circulation. 2000;102(13):1503-1510.

11. Nissen SE, Tuzcu EM, Libby P, et al. Effect of antihypertensive agents on cardiovascular events in patients with coronary disease and normal blood pressure: the CAMELOT study: a randomised controlled trial. JAMA. 2004;292(18):2217-2225.

12. Julius S, Kjeldsen SE, Weber M, et al. Outcomes in hypertensive patients at high cardiovascular risk treated with regimens based on valsartan or amlodipine: the VALUE randomized trial. Lancet. 2004;363(9426):2022-2031. 
13. Dahlöf B, Sever PS, Poulter NR, et al. Prevention of cardiovascular events with an antihypertensive regimen of amlodipine adding perindopril as required versus atenolol adding bendroflumethiazide as required, in the Anglo-Scandinavian Cardiac Outcomes Trial-Blood Pressure Lowering Arm (ASCOT-BPLA): a multicentre randomised controlled trial. Lancet. 2005;366(9489):895-906.

14. Jamerson K, Weber MA, Bakris GL, et al. Benazepril plus amlodipine or hydrochlorothiazide for hypertension in high-risk patients. $N$ Engl J Med. 2008;359(23):2417-2428.

15. The effect of diltiazem on mortality and reinfarction after myocardial infarction. The Multicenter Diltiazem Postinfarction Trial Research Group. N Engl J Med. 1988;319(7):385-392.

16. Elkayam U, Amin J, Mehra A, Vasquez J, Weber L, Rahimtoola SH. A prospective, randomized, double-blind, crossover study to compare the efficacy and safety of chronic nifedipine therapy with that of isosorbide dinitrate and their combination in the treatment of chronic congestive heart failure. Circulation. 1990;82(6):1954-1961.

17. Packer M, O'Connor CM, Ghali JK, et al. Effect of amlodipine on morbidity and mortality in severe chronic heart failure. Prospective Randomized Amlodipine Survival Evaluation Study Group. $N$ Engl J Med. 1996;335(15):1107-1114.

18. Ogihara T, Nakao K, Fukui T, et al. Effects of candesartan compared with amlodipine in hypertensive patients with high cardiovascular risks: candesartan antihypertensive survival evaluation in Japan trial Hypertension. 2008;51:393-398.

19. Deanfield JE, Detry JM, Lichtlen PR, Magnani B, Sellier P, Thaulow E. Amlodipine reduces transient myocardial ischemia in patients with coronary artery disease: double-blind Circadian Anti-Ischemia Program in Europe (CAPE Trial). J Am Coll Cardiol. 1994;24(6): 1460-1467.

20. Klag MJ, Whelton PK, Randall BL, et al. Blood pressure and end-stage renal disease in men. $N$ Engl J Med. 1996;334(1):13-18.

21. Arulkumaran N, Diwakar R, Tahir Z, Mohamed M, Kaski JC, Banerjee D. Pulse pressure and progression of chronic kidney disease. J Nephrol. 2010;23(2):189-193.

22. Rahman M, Pressel S, Davis BR, et al. Renal outcomes in high-risk hypertensive patients treated with an angiotensin-converting enzyme inhibitor or a calcium channel blocker vs a diuretic: a report from the Antihypertensive and Lipid-Lowering Treatment to Prevent Heart Attack Trial (ALLHAT). Arch Intern Med. 2005;165(8):936-946.
23. Agodoa LY, Appel L, Bakris GL, et al. Effect of ramipril vs amlodipine on renal outcomes in hypertensive nephrosclerosis: a randomized controlled trial. JAMA. 2001;285(21):2719-2728.

24. Wright JT Jr, Bakris G, Greene T, et al. Effect of blood pressure lowering and antihypertensive drug class on progression of hypertensive kidney disease: results from the AASK trial. JAMA. 2002;288(19): 2421-2431.

25. Bakris GL, Sarafidis PA, Weir MR, et al. Renal outcomes with different fixed-dose combination therapies in patients with hypertension at high risk for cardiovascular events (ACCOMPLISH): a prespecified secondary analysis of a Randomized controlled trial. Lancet. 2010; 375(9721):1173-1181.

26. Oparil S, Chrysant SG, Melino M, Lee J, Karki S, Heyrman R. Long-term efficacy of a combination of amlodipine and olmesartan medoxomil +/- hydrochlorothiazide in patients with hypertension stratified by age, race and diabetes status: a substudy of the $\mathrm{COACH}$ trial. J Hum Hypertens. 2010;24(12):831-838.

27. Brown MJ, McInnes GT, Papst CC, Zhang J, MacDonald TM. Aliskiren and the calcium channel blocker amlodipine combination as an initial treatment strategy for hypertension control (ACCELERATE): a randomised, parallel-group trial. Lancet. 2011;377(9762):312-320. Epub Jan 12, 2011.

28. Ogawa H, Kim-Mitsuyama S, Jinnouchi T, Matsui K, Arakawa K. Rationale, design and patient baseline characteristics of OlmeSartan and calcium antagonists randomized (OSCAR) study: a study comparing the incidence of cardiovascular events between high-dose angiotensin II receptor blocker (ARB) monotherapy and combination therapy of $\mathrm{ARB}$ with calcium channel blocker in Japanese elderly high-risk hypertensive patients (ClinicalTrials.gov no. NCT00134160). Hypertens Res. 2009;32(7):575-580.

29. IMS Health. Pharmaceutical.org.uk. Available at: http://www. pharmaceutical.org.uk/pharmaceutical-product/index.html. Accessed July 24, 2011.
Integrated Blood Pressure Control

\section{Publish your work in this journal}

Integrated Blood Pressure Control is an international, peer-reviewed open-access journal focusing on the integrated approach to managing hypertension and risk reduction. Treating the patient and comorbidities together with diet and lifestyle modification and optimizing healthcare resources through a multidisciplinary team approach constitute key

\section{Dovepress}

features of the journal. This journal is indexed on American Chemical Society's Chemical Abstracts Service (CAS). The manuscript management system is completely online and includes a very quick and fair peerreview system, which is all easy to use. Visit http://www.dovepress.com/ testimonials.php to read real quotes from published authors. 